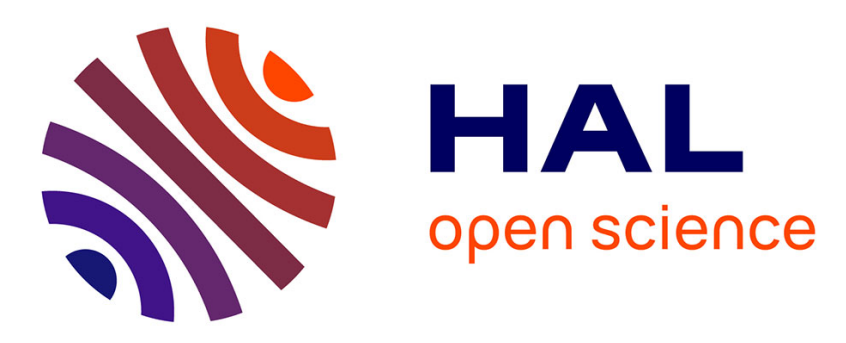

\title{
Evolution of the linear chromosomal DNA in Streptomyces: is genomic variability developmentally modulated?
}

Annie Dary, Patricia Martin, Thomas Wenner, Pierre Leblond, Bernard

Decaris

\section{To cite this version:}

Annie Dary, Patricia Martin, Thomas Wenner, Pierre Leblond, Bernard Decaris. Evolution of the linear chromosomal DNA in Streptomyces: is genomic variability developmentally modulated?. Research in Microbiology, 1999, 150 (7), pp.439-445. hal-01659000

\section{HAL Id: hal-01659000 \\ https://hal.univ-lorraine.fr/hal-01659000}

Submitted on 8 Dec 2017

HAL is a multi-disciplinary open access archive for the deposit and dissemination of scientific research documents, whether they are published or not. The documents may come from teaching and research institutions in France or abroad, or from public or private research centers.
L'archive ouverte pluridisciplinaire HAL, est destinée au dépôt et à la diffusion de documents scientifiques de niveau recherche, publiés ou non, émanant des établissements d'enseignement et de recherche français ou étrangers, des laboratoires publics ou privés. 


\title{
Mini-review
}

\section{Evolution of the linear chromosomal DNA in Streptomyces: is genomic variability developmentally modulated?}

\author{
Annie Dary*, Patricia Martin, Thomas Wenner, Pierre Leblond, Bernard Decaris \\ Laboratoire de génétique et microbiologie associé à l'Institut national de la recherche agronomique (unité 952), \\ faculté des sciences de l'université Henri Poincaré, Nancy 1, BP239, 54506 Vandoeuvre-Lès-Nancy, France
}

(Submitted 3 June 1999; accepted 8 July 1999)

\begin{abstract}
Genome rearrangements are responsible for the variability observed at the ends of the chromosome among Streptomyces species. The characterization of mutators, which are stimulated for genome plasticity, and of mutants produced at different stages of development support the idea that genome instability is developmentally modulated. (C) 1999 Éditions scientifiques et médicales Elsevier SAS
\end{abstract}

genomic instability / Streptomyces / developmental control

\section{Introduction}

Genetic polymorphism is requisite for the evolutionary process since the generation of mixed populations consisting of various phenotypes ensures that a small fraction of organisms already expressing the appropriate phenotype will survive a sudden environmental change. Various mutagenic mechanisms affecting nucleotide sequence and/or genetic organization generate polymorphisms among populations. Therefore, genome rearrangements play an important role in the creation of biodiversity and ultimately in evolution. Analyses of genomic diversity among organisms revealed that genome rearrangements have a major impact during the evolution of the genome. Inversions, deletions, duplications and translocations create new DNA associations potentially coding for proteins with new combinations of functional domains. Further, they may modify gene expression by changing their relative positioning

\footnotetext{
* Correspondence and reprints

dary@scbiol.u-nancy.fr

Abbreviations: AUD, amplifiable unit of DNA; DSB, doublestrand break; npc, number of papillae per colony; TIR, terminal inverted repeat
}

within the genome, and, hence, the local environment of specific genes. Duplication of genes or even genomes [35] allows the acquisition of new functions via the accumulation of mutations. Loss of functions may be advantageous by simplifying a complex apparatus to a more efficient system. Finally, insertion of foreign DNA, i.e., horizontal gene transfer, facilitates the flow of genes between unrelated species and allows the acquisition of new traits [2]. The case of pathogenic bacteria nicely illustrates the important role that genome rearrangement can play, as it is easy to detect the advantage conferred by some genome rearrangements in this system. Indeed, genome rearrangements are important for the survival of pathogenic bacteria, either by switching on and off individual genes and allowing for antigenic variation, by creating new gene variants, or for the acquisition of new pathogenicity characteristics from other bacteria $[8,13,21]$. Rearrangements can affect few or many chromosomal loci. Rearrangements which affect multiple loci create more diversity than those which are specific for certain genes. In this sense, Streptomyces bacteria are remarkable, exhibiting a high frequency of genome rearrangements with the potential to affect several hundred to more than two thousand kilobases [15]. 
On solid medium, Streptomyces colonies are highly differentiated. They consist of vegetative mycelium with radial growth, aerial mycelium, and spores. This morphological differentiation is associated with a physiological differentiation. Thus, the different parts of a single colony exhibit different physiological states. Mycelium of Streptomyces are coenocytic with each hyphal compartment containing numerous copies of the chromosome. The majority of spores, on the other hand, seem to contain a single copy. Finally, the different compartments of Streptomyces colonies communicate by intracellular and extracellular signals which change during the different steps of differentiation. This complex life cycle is associated with the production of a great variety of secondary metabolites which have attracted economic interest as antibiotics [6].

\section{Genome plasticity shapes the Streptomyces genome}

Streptomyces chromosomal DNA is a linear molecule approximately $8 \mathrm{Mb}$ in length in all species tested thus far. It has a typical invertron structure characterized by the presence of terminal inverted repeats (TIRs) covalently bound to proteins [17]. The presence of TIRs appears to be a characteristic of all Streptomyces linear replicons. A bidirectional replication origin located at the approximate center of the chromosome $[11,22]$ allows the determination of two similarly sized chromosomal arms (figure 1). The chromosomal DNA might adopt a structure in which the terminal repeats synaptically associate, as in the 'racket frame' model which was proposed for the linear plasmid SCP1 [27].

Streptomyces chromosomal DNA is prone to large deletions including genes previously reported to be genetically unstable. Most of these genes are associated with secondary metabolism. Up to $25 \%$ of the genome can be deleted without affecting the survival of the corresponding mutant under laboratory conditions. In some cases, deletions are associated with large-scale DNA amplification resulting from the tandem reiteration of an amplifiable unit of DNA (AUD) [15]. All of these rearrangements are located at the ends of the chromosomal DNA. Several types of mutants, which differ in the size of the deleted sequences as well as in the structure of their chromosomal DNA, can be observed (figure 1). Mutants having a deletion located on one or both chromosomal extremities constitute the two first types of mutants which are observed (figure $1 A, B$; $[10,25]$ ). Both types of mutants display TIRs reduced in length, with the second type being extreme. In the first case, the chromosomal DNA remains linear (figure 1A) while in the second case, deletion of the TIRs leads to a circularization of chromosomal DNA (figure 1B). Mutants harboring linear chromosomal DNA where the size of the TIRs has increased characterize a third category of mutants [12]. Two mutants harboring chromosomal DNA with TIRs of $480 \mathrm{~kb}$ and $850 \mathrm{~kb}$, respectively, have been isolated. In these mutants, one chromosomal end has been deleted and replaced by a sequence identical to the end of the undeleted extremity (figure 1C). This replacement results from a homologous recombination event occurring between two copies of a duplicated sequence (the has gene) on the $S$. ambofaciens chromosome. Each chromosomal extremity contains a copy of the has gene which is located outside of the TIRs and at different distances from the chromosome end. The replacement of one end by another could result from a single nonallelic crossover between the two copies of the has gene. Finally, mutants lacking an extremity but still possessing a conserved linear chromosomal structure can also be observed (figure 1D; [10, 25]). Some mutants in this category exhibit amplification. However, the nature of the new chromosome end remains thus far unknown. Genome plasticity is probably responsible for chromosomal end diversity observed among the Streptomyces species. The TIRs are highly polymorphic and exhibit changes in both size and nucleotide sequence. For example, Streptomyces coelicolor, Streptomyces lividans, and Streptomyces ambofaciens are phylogenetically closely related [29]; however, the TIRs of $S$. lividans and $S$. ambofaciens do not 


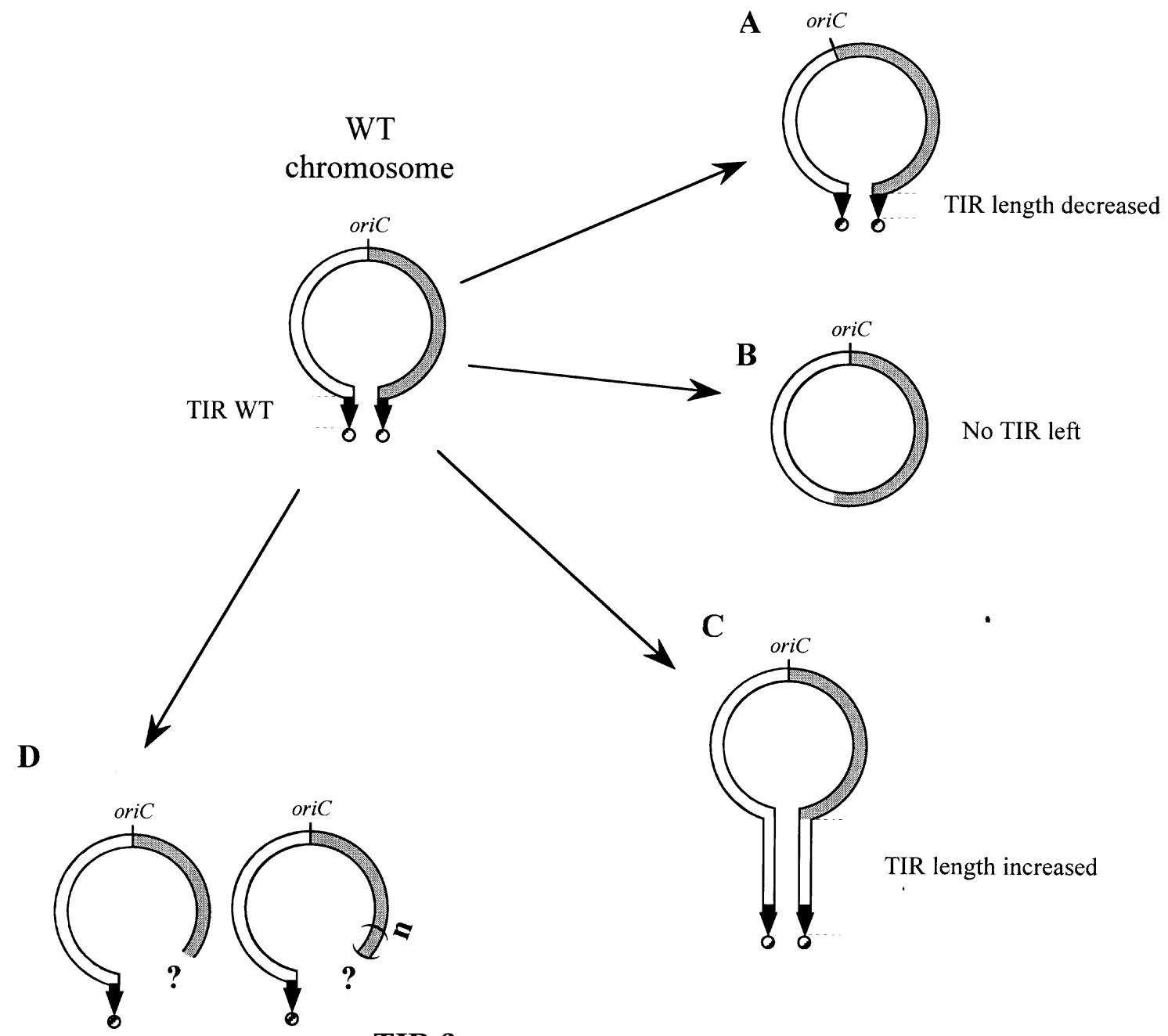

TIR ?

Figure I. Types of mutant chromosomal DNA generated by genome plasticity in Streptomyces. A. Mutant chromosomal DNA harboring a deletion on one chromosomal arm and TIRs which are reduced in size. B. Circular mutant chromosomal DNA deleted for both extremities. C. Mutant chromosomal DNA with TIRs of increased lengh. One extremity has been deleted and replaced by the other extremity. D. Mutant chromosomal DNA deleted for one extremity and remaining linear. The position of the replication origin (oriC) is indicated by a vertical line. The horizontal dashed lines mark the TIRs on each type of chromosomal DNA. The amplification of an amplifiable unit of DNA is symbolized by the brackets in D and the number of reiterated copies are desiganted by ' $n$ '. The question marks represents the unknown structure of the extremity in the chromosomal mutant DNA portrayed in D.

share any homology. Furthermore, the last $30 \mathrm{~kb}$ of the TIRs of S. ambofaciens DSM40697 do not exist in S. ambofaciens ATCC23877 [12]. Such differences between two strains of the same species involve either deletion events or the acquisition of a new extremity. The interaction of chromosomal DNA with a linear replicon can lead to the acquisition of a new extremity and such events have been observed by others. In one case, the TIRs ends of the S. lividans chromosomal DNA are similar to one end of the linear plasmid SLP2 [17]. Exchanges of DNA ends between linear plasmid pPZG101 and the chromosomal DNA in S. rimosus have also been 
reported [24] and result in a hybrid chromosome. As the invertron structure appears to be conserved among Streptomyces linear replicons, Fischer et al. [12] propose that the maintenance of this structure could be achieved in the hybrid chromosome by an interchromosomal exchange, similar to that postulated for the mutants possessing extended TIRs (figure 1C).

Chromosomal extremities correspond to regions which are not silent but contain numerous genes. Sequencing data as well as the analysis of gene expression using two-dimensional gel electrophoresis of proteins revealed that deletions result in important alterations of the physiology of mutants which display a pleiotropic phenotype $[7,15]$. Genes involved either in resistance and/or antibiotic biosynthesis have been located at the extremities of the chromosome of Streptomyces glaucescens, Streptomyces achromogenes, Streptomyces fradiae, S. lividans, and Streptomyces rimosus. In S. ambofaciens, sequencing of the AUD6 and AUD90 revealed the presence of repressor-like and a pKS-like gene [15, 24].

Genome rearrangements modulate genome expression either by creating new DNA associations, by gene acquisition, or by gene dosage. Thus, in the $S$. ambofaciens mutants with extended TIRs (figure 1C) the has genes, where the recombination event occurs, encode a putative sigma factor. Such an event results in the creation of potentially functional chimeric genes having new regulation signals [12]. In S. rimosus, the interaction between the ends of the chromosomal DNA and the plasmid pPZG101 allows the acquisition of the oxytetracycline biosynthesis cluster [24]. Finally, in S. ambofaciens, the amplification of the AUD90 results in both spiramycin biosynthesis inhibition and depletion of lipid content. In addition, a new product was detected in the amplified mutant culture. We proposed that gene dosage of the PKS gene included in the AUD90 was responsible for this effect and that precursors required for both spiramycin and lipid biosynthesis were deviated towards synthesis of the new product in response to changes in AUD90 PKS gene dosage [28].

\section{A putative developmental modulation of genome plasticity}

Little is known about functions able to control genome integrity, i.e., to either promote or repress genomic instability. At least two alternate strategies can be used to identify such functions. The first consists of testing the effects of mutations in genes already known to be involved in the control of genome integrity in other bacteria [3]. The second consists of isolating strains displaying a different level of genome instability.

The first strategy can be directly deduced from the results of treatments stimulating genome instability. Indeed, various treatments, mutagenic or not, are able to induce genome rearrangements. UV exposure or growth in the presence of intercalating agents (ethidium bromide, acridine orange, acriflavine) induce genome instability, at survival rates which are higher than those used in classic mutagenesis. These mutants harbored the same type of rearrangements as the spontaneous ones [33]. Antibiotics known to inhibit DNA gyrase (novobiocin or oxolinic acid) also stimulate genetic instability [34]. Other treatments which are not mutagenic but biologically stressful such as cold storage or protoplastization also induce genetic instability. Therefore, the induction of genomic instability by some treatments suggested that an SOS-like response was involved. Hence, the recA gene has been cloned from $S$. lividans [23] and $S$. ambofaciens [1]. A mutant exhibiting reduced homologous recombination activity was obtained in S. lividans. In this mutant, the deletion frequency at the end of the chromosome is enhanced while its ability to amplify DNA has been lost. These results show that the protein RecA could play a role in genomic plasticity [32].

The second strategy was developed in S. ambofaciens and allowed us to observe very high intraclonal variability within the same strain. In this species, pigmentation of the colonies is highly mutable and leads to pigmented colonies harboring one or several sectors ( $\mathrm{Pig}^{+} \mathrm{sec}$; figure $2 \mathrm{~A}$ ) and/or white papillae (Pig ${ }^{+}$pap; 

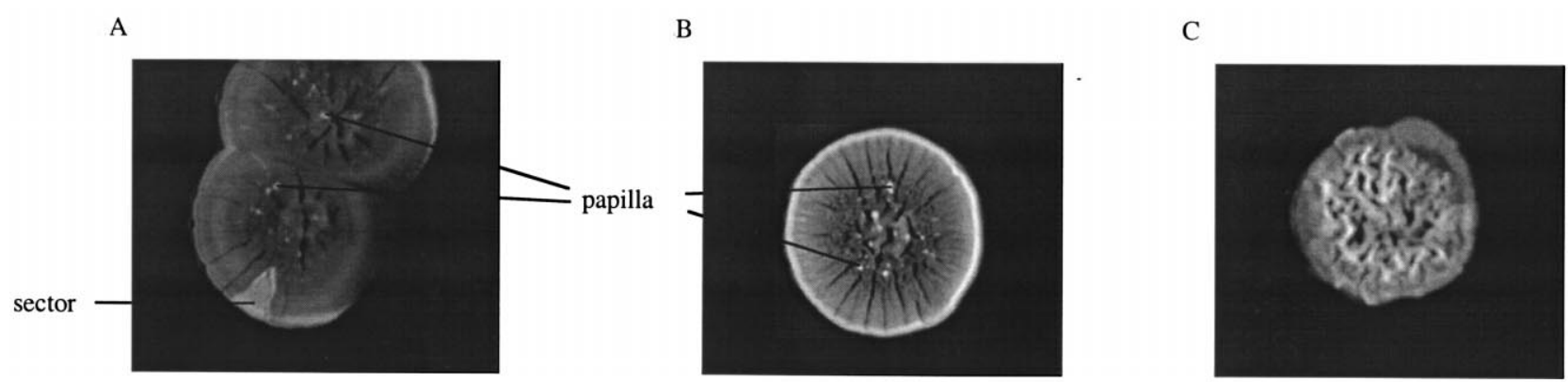

Figure 2. Different types of colonies observed in a S. ambofaciens culture. Pigmented colony with A. a pigment-defective sector and papillae; B. pigmented colony with pigment-defective papillae; C. pigment-defective colony.

figure $2 B$ ) and pigment-deficient colonies (Pig ${ }^{-} \mathrm{col}$; figure 2C). Sectors are thought to result from a mutational event incurred during vegetative mycelium growth, while papillae result from a mutational event arising during aerial mycelium differentiation. The $\mathrm{Pig}^{-} \mathrm{col}$ mutants arise from the germination of a mutant spore which can be formally produced by a sector, a papilla, or a mutational event occurring during sporogenesis. $\mathrm{Pig}^{-} \mathrm{col}, \mathrm{Pig}^{-} \mathrm{sec}$, and $\mathrm{Pig}^{-}$pap are not the result of the same mutational event arising at different stages of colony development. Genome rearrangements are only detected in the pigment-defective mutants derived from sectors ( $\left.\mathrm{Pig}^{-} \mathrm{sec}\right)$ or colonies $\left(\mathrm{Pig}^{-} \mathrm{Col}\right)$ but not from papillae (Pig-pap). The Pig-pap mutants share characteristics which distinguish them from the two other types of mutants: they are unable to sporulate and do not possess deletions at the ends of the chromosome [19, 31]. They correspond to a new aspect of genetic instability in S. ambofaciens. The $\mathrm{Pig}^{-} \mathrm{col}$ and $\mathrm{Pig}^{-} \mathrm{sec}$ mutants are phenotypically heterogeneous and the two types of mutants cannot be differentiated based on phenotype alone. However, the occurrence of deletions was at least tenfold lower in the $\mathrm{Pig}^{-} \mathrm{Sec}$ than in the $\mathrm{Pig}^{-} \mathrm{col}$ mutants (figure $3 A, B$ ). Such a deficit of deletion between mutants, produced by mutational events incurred during different developmental stages, suggests that the occurrence of rearrangements could depend upon the morphological development of colonies.

In a $S$. ambofaciens culture most colonies exhibit papillae. The number of papillae per colony (npc) is genetically determined and constitutes a good indicator to isolate mutators. Thus, colonies having more than 20 papillae (hyperpap colonies) predominantly produce hyperpap colonies while the colonies with few papillae essentially produce colonies with a small number of papillae in their progeny. The hyperpap colonies correspond to mutators which are stimulated for genetic instability. In these mutators only colony pigmentation and sporulation seem to be affected [19]. Analysis of genetic instability in the WT and mutator subpopulations has revealed some common features. First, the level of mutability during the aerial mycelium differentiation, which is measured by the npc, varies between the WT and mutators. Second, the level of genetic instability,

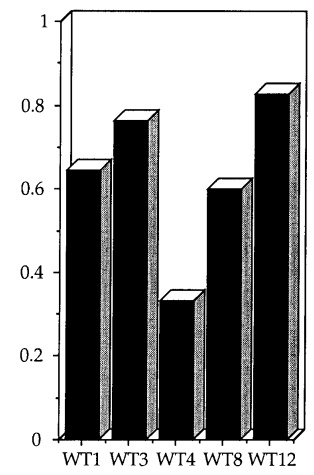

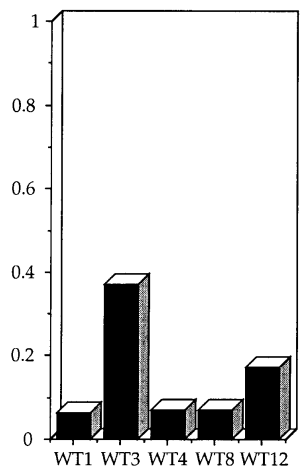

Figure 3. Frequency of deletion at the chromosomal extremities among pigment-defective mutants arising either from $\mathbf{A}$. pigment-defective colonies or B. sectors and isolated in five different progenies. 
measured by the frequencies of $\mathrm{Pig}^{-} \mathrm{col}$ and $\mathrm{Pig}^{-}$sec, varied between the subpopulations as do frequencies of deletion in pigment-defective mutants. Finally, analysis of mutants harboring a deletion and isolated in five independent WT progenies has revealed that two WT subclones predominantly produce mutants which are deleted on the right chromosomal arm (unpublished results). Such results reveal an endogeneous modulation of genome instability suggesting that WT subclones and mutators could display different degrees of the same mutator state.

\section{Discussion}

As a functional bidirectional replication origin is present at the approximate center of the chromosome, the extremities probably correspond to regions of replication completion. A correlation between the termination of replication and genomic instability might exist [15]. Indeed, such regions are known to be highly variable in circular or linear chromosomes. In Escherichia coli this region contains specific sequences (Ter sites) where the replication fork is slowed. The arrest of the replication fork is known to be at the origin of genome rearrangement via illegitimate or homologous recombination events [4]. In E. coli, double-strand breaks (DSBs) related to replication fork arrest are processed by recombination events requiring $\operatorname{Rec} A$ and RecBCD [20]. Arrest of replication fork progression can be caused by exogenous factors such as irradiation, or treatment by substances that increase the frequency of DSBs like oxolinique acid. Endogenous factors, like the nature of the DNA sequence or secondary structures, can also slow down or stop the replication fork. Finally, replication can stop at specific sites during a response to stress, like the stringent response [16]. In Streptomyces, some specific sequences located at the chromosome ends might slow the replication forks on each arm [14], explaining the high occurrence of rearrangements at the chromosome ends.

In the preceding section, we proposed that rearrangements could preferentially occur at specific developmental stages. Such a hypothesis is based on the deficit of deletions observed between the $\mathrm{Pig}^{-} \mathrm{Col}$ and the $\mathrm{Pig}^{-} \mathrm{sec}$ mutants. The Pig ${ }^{-}$pap are distinct from the $\mathrm{Pig}^{-} \mathrm{col}$ and Pig $^{-}$sec since they are not deleted, are phenotypically homogeneous, and probably correspond to another aspect of genetic instability in $S$. ambofaciens. Pigment-defective sectors probably result from a mutational event occurring during vegetative mycelium growth, probably during a rapid phase of growth since nutrients are not limited. The differentiation of vegetative mycelium into a aerial mycelium requires different signals including the ppGpp which initiates the stringent response in response to limited nitrogen [5]. As in Bacillus subtilis, such a response might slow down or stop the replication forks at specific sites, favoring genomic rearrangements. Therefore, during the sporulation process, DSBs could be more frequent.

Pauses in the replication fork can also induce small rearrangements, i.e., deletion or duplication of a few base pairs [9]. Pig ${ }^{-}$pap could result from such a mutational event occurring during aerial mycelium formation, as has been proposed for recombination-dependent mutations during the stationary phase [26].

Finally, numerous reports have found that under some conditions, a fraction of a population can become mutator, at least transiently [18]. The presence of such mutators could have a major impact on the adaptation of the population [30]. In S. ambofaciens, we observed that different subclones displayed different level of genetic instability. Accordingly, we proposed that they harbored a different degree of the same mutator state. Although the nature of such a mutator state remains unknown, the relationship observed between the number of papillae and the extent of the mutator state suggests that this state results from a quantitative modification such as the repetition of a monotonous nucleotidic sequence within or near a gene controlling genome integrity or an epigenetic modification. Such a mutator state might develop when conditions become limiting during the Streptomyces lifespan, leading to a modulation of genomic instability. 


\section{References}

[I] Aigle B., Holl A.C., Angulo J.F., Leblond P., Decaris B., Characterization of two Streptomyces ambofaciens recA mutants identification of the RecA protein by immunoblotting, FEMS Microbiol. Lett. I49 (I997) I8I-I87.

[2] Arber W., Evolution of prokaryotic genome, Gene I35 (1993) 49-56.

[3] Baltz R.H., Seno E.T., Genetics of Streptomyces fradiae and tylosin biosynthesis, Annu. Rev. Microbiol. 42 (1988) 547-574.

[4] Bierne H., Michel B., When the replication forks stop, Mol. Microbiol. 13 (1994) I7-23.

[5] Chakraburtty R., Bibb M., The ppGpp synthetase gene (relA) of Streptomyces coelicolor A3 (2) plays a conditional role in antibiotic production and morphological differentiation, J. Bacteriol. I79 (1997) II 68-I I74.

[6] Chater K.F., Taking a genetic scalpel to the Streptomyces colony, Microbiology I44 (1998) I465-I478.

[7] Dary A., Kaiser P., Bourget N., Thompson C.J., Simonet J.M., Decaris B., Large genomic rearrangements of the unstable region in Streptomyces ambofaciens are associated with major changes in global gene expression, Mol. Microbiol. 10 (I993) 759-769.

[8] Dybvig K., DNA rearrangements and phenotypic swithching in prokaryotes, Mol. Microbiol. 10 (I993) 465-47I.

[9] Farabaugh P.J., Schmeisser U., Hofer M., Miller J.H., Genetic studies of the lac repressor. VII. On the molecular nature of spontaneous hot spot in the lacl gene of Escherichia coli, J. Mol. Biol. I 26 (1978) 847-857.

[10] Fischer G., Decaris B., Leblond P., Occurrence of deletions associated with genetic instability in Streptomyces ambofaciens is independent of the linearity of the chromosomal DNA, J. Bacteriol. 179 (1997) 4553-4558.

[II] Fischer G., Holl A.C., Volff J.N., Vandewiele D., Decaris B., Leblond P., Replication of the linear chromosomal DNA from the centrally located oriC of Streptomyces ambofaciens revealed by PFGE gene dosage analysis, Res. Microbiol. 149 (1998) 203-210.

[12] Fischer G., Wenner T., Decaris B., Leblond P., Chromosomal arm replacement generates a high level of intraspecific polymorphism in the terminal inverted repeats of the linear chromosomal DNA of Streptomyces ambofaciens, Proc. Natl. Acad. Sci. USA 95 (1998) |4296-|430|.

[13] Groisman E.A., Ochman H., How Salmonella became a pathogen, Trends Microbiol. 5 (1997) 343-349.

[14] Huang C.H., Lin Y.S., Yang Y.L., Huang S.W., Chen C.W., The telomeres of Streptomyces chromosomes contain conserved palindromic sequences with potential to form complex secondary structures, Mol. Microbiol. 28 (1998) 905-916.

[15] Leblond P., Decaris B., Unstable linear chromosomes: the case of Streptomyces, in: Charlebois R.L. (Ed.), Organization of the prokaryotic genome, American Society for Microbiology, Washington DC, 1999 , in press.

[16] Levine A., Autret S., Serror S.J., A checkpoint involving RTP the replication terminator protein arrests replication downstream of the origin during the stringent response in Bacillus subtilis, Mol. Microbiol. I5 (1995) 287-295.

[17] Lin Y.S., Kieser H., Hopwood D.A., Chen C.W., The chromosomal DNA of Streptomyces lividans 66 is linear, Mol. Microbiol. 10 (1993) 923-933.
[18] Mao E.F., Lane L., Lee J., Miller J.H., Proliferation of mutators in a cell population, J. Bacteriol. 179 (1997) 4I7-422.

[19] Martin P., Dary A., Decaris B., Generation of a genetic polymorphism in clonal populations of the bacterium Streptomyces ambofaciens: characterization of different mutator states, Mutat. Res. 42I (I998) 73-82.

[20] Michel B., Ehrlich S.D., Uzest M., DNA double-strand breaks caused by replication arrest, EMBO J. 16 (I997) 430-438.

[2I] Moxon E.R., Rainey P.B., Nowak M.A., Lenski R.E., Adaptative evolution of highly mutable loci in pathogenic bacteria, Curr. Biol. 4 (I994) 24-33.

[22] Musialowski M.S., Flett F., Scott G.B., Hobbs G., Smith C., Oliver S.G., Functional evidence that the principal DNA replication origin of the Streptomyces coelicolor chromosome is close to dnaA-gyrB region, J. Bacteriol. 176 (I994) 5I23-5I25.

[23] Muth G., Frese D., Kleber A., Wohlleben W., Mutational analysis of the Streptomyces lividans recA gene suggests that only mutants with residual activity remain viable, Mol. Gen. Genet. 255 (1997) 420-428.

[24] Pandza S., Biukovic G., Paravic A., Dadbin A., Cullum J., Hranueli D., Recombination between the linear plasmid PPZG IOI and the linear chromosome of Streptomyces rimosus can lead to exchange of ends, Mol. Microbiol. 28 (1998) II65-II76.

[25] Rauland U., Glocker I., Redenbach M., Cullum J., DNA amplifications and deletions in Streptomyces lividans 66 and the loss of one end of the linear chromosome, Mol. Gen. Genet. 246 (I 995) 37-44.

[26] Rosenberg S.M., Thulin C., Harris R.S., Transient and heritable mutators in adaptative evolution in the lab and in nature, Genetics 148 (1998) I559-I566.

[27] Sakaguchi K., Invertrons a class of structurally and functionally related genetic elements that include linear DNA plasmids transposable elements and genome of adeno-type viruses, Microbiol. Rev. 54 (1990) 66-74.

[28] Schauner C., Dary A., Lebrihi A., Leblond P., Decaris B., Germain P., Modulation of lipid metabolism and spiramycin biosynthesis in Streptomyces ambofaciens unstable mutants, Appl. Environ. Microbiol. 65 (1999) 2730-2737.

[29] Stackebrandt E., Liesack W., Witt D., Ribosomal RNA and rDNA sequence analyses, Gene II5 (1992) 255-260.

[30] Taddei F., Radman M., Maynard-Smith J., Toupance B., Gouyon P.H., Godelle B., Role of mutator alleles in adaptative evolution, Nature 387 (1997) 700-702.

[3 I] Vandewiele D., Volff J.N., Aigle B., Simonet J.M., Decaris B., Isolation and characterization of a mutator strain of Streptomyces ambofaciens ATCC23877 exhibiting an increased level of genetic instability, Can. J. Microbiol. 42 (I996) 562-570.

[32] Volff J.N.,, Altenbuchner J., Influence of disruption of the recA gene on genetic instability and genome rearrangement in Streptomyces lividans, J. Bacteriol. 179 (1997) 2440-2445.

[33] Volff J.N., Vandewiele D., Simonet J.M., Decaris B., Ultraviolet light mitomycin $C$ and nitrous acid induce genetic instability in Streptomyces ambofaciens ATCC23877, Mutat. Res. 287 (1993) I4I-I56.

[34] Volff J.N., Vandewiele D., Simonet J.M., Decaris B., Stimulation of genetic instability in Streptomyces ambofaciens ATCC23877 by antibiotics that interact with DNA gyrase, J. Gen. Microbiol. I 39 (1993) $255 \mathrm{I}-2558$.

[35] Wolfe K.H., Shields D.C., Molecular evidence for an ancient duplication of the entire yeast genome, Nature 387 (1997) 708-7I3. 